Case Report

\title{
Incidence of various medication errors in pediatrics in a tertiary care hospital
}

\author{
Chandra Deve Varma BSK ${ }^{1}$, Balaji Bhusan Patnaik ${ }^{2}$, Ratakonda Sruthi ${ }^{3}$, Gangavaram sravan kumar Reddy ${ }^{4}$, \\ V.Venkatesh ${ }^{5}$, Jogi Satyasree ${ }^{6}$ \\ ${ }^{1}$ Dr. Chandra Deve Varma BSK, Assistant Professor, ${ }^{2}$ Dr. Balaji Bhusan Patnaik, Assistant Professor, Pediatrics, \\ Maharajah's Institute of Medical Sciences, Nellimarla, ${ }^{3}$ Dr. Ratakonda Sruthi, ${ }^{4}$ Dr. Gangavaram sravan kumar Reddy, \\ ${ }^{5}$ Dr. V. Venkatesh, ${ }^{6}$ Dr. Jogi satyasree, Post Graduates, Pediatrics, Maharajah's Institute of Medical Sciences, Nellimarla. \\ Nellimarla, Vizianagaram District, Andhra Pradesh, India.
}

Corresponding Author: Dr. Balaji Bhusan Patnaik, Assistant Professor, Pediatrics, Maharajah's Institute of Medical Sciences, Nellimarla, Vizianagaram District, Andhra Pradesh, India. Email: drkishore018@gmail.com

\begin{abstract}
Background: Medication errors in pediatrics are an important cause of iatrogenic disease in hospital patients [1]. Despite this, studies regarding the medication errors in India are very few. Aims: To determine the incidence and type of errors in a tertiary care hospital over a period of 4 months. Material and methods: It is a prospective observational study. Medication errors were documented instandard reporting forms from April 2018 to July 2018. Main outcome measures were incidence and types of medication errors in pediatrics. Results: The medication error was 1 per 9.5 patients i.e, $10.5 \%$. The dispensing errors and clerical errors constituted $66.04 \%$ of all errors. Maximum medication error was found under the age of 2 years (49.07\%). Incorrect IV infusion rate was $24.90 \%$ followed by prescribing incorrect dose $21.97 \%$. Most common drugs implicated in medication errors were IV fluids followed by IV antibiotics. Conclusion: Adequate number of staff and electronic mode of prescription and compulsory documentation of errors will reduce iatrogenic errors significantly.
\end{abstract}

Key words: Iatrogenicerrors, Medication errors, Prescription errors

\section{Introduction}

The united states pharmacopeia defines medication errors as any preventable event that may cause or lead to an inappropriate medication use or patient harm while the medication use or patient harm while the medication is in control of the healthcare professional, patient or consumer [1,2]. A number of types of medication errors, such as prescribing errors or medication administration errors, have been recognized [3]. In the past 10 years, medication errors have come to be recognized as an important cause of iatrogenic disease in hospital patients [4-7].

Noncompliance and iatrogenic errors in medication is an important cause of treatment failure [8-10]. In developing countries, it is compounded by overcrowding, poverty, ignorance [11]. In the hospital all the drugs a patient is given are under the control of treating physician and patient compliance especially in

Manuscript received: $30^{\text {th }}$ August 2018

Reviewed: $8^{\text {th }}$ September 2018

Author Corrected: $16^{\text {th }}$ September 2018

Accepted for Publication: $20^{\text {th }}$ September 2018 pediatric age group can be ensured to maximum. Nevertheless, errors may occur may occur and wrong drug or dose be given to patient. In infants and children a greater magnitude of errors is likely to occur because of small body size and calculation of dose on basis of weight.

While many errors are minor those associated with morbidity and mortality increase health care costs and can be a source of litigation [1]. Despite this and apart from case report advices and guidelines little has been published on medication errors in children in hospital.

\section{Material and Methods}

Study design: It is a prospective observational study of 2600 patients upto 14 years.

Study period: The study is conducted over a period of 4 months (April 2018 to July 2018)

Study Place: General pediatric ward, Pediatric ICU and Neonatal ICU of Maharaja's Institute of Medical Sciences, Nellimarla, Andhra Pradesh. 


\section{Case Report}

\section{Inclusion criteria}

1. Patients admitted in general pediatric ward, Pediatric ICU and Neonatal ICU of Age14 years and below.

2. All the doctors and nurseswere told to report any errors observed in prescribing, preparing and giving out medicines. All the errors were reported to authors within 24 hours and they were confirmed by author.

Exclusion Criteria: The number of drugs prescribed or to look for medical error during the period were not recorded.

\section{Results}

During the study period 2600 patients upto 14 years of age were admitted. The daily census ranged from 15 to 25 in the ward and ICU. Our pediatric department has a bed strength of 60 with 5 nurses were posted at a time round the clock in 8-hour shift duties. Average bed occupancy during the period was 110 to $120 \%$. 273 medication related errors were reported during the 4 months study period. Inadequate clinical response to standard treatment protocol and appearance of new symptoms which could to ascribed to toxicity of prescribed drugs were the main indicators leading to detection of errors. However, some errors were observed during routine clinical rounds and also by nurses while giving medication.

\section{Number of patients}

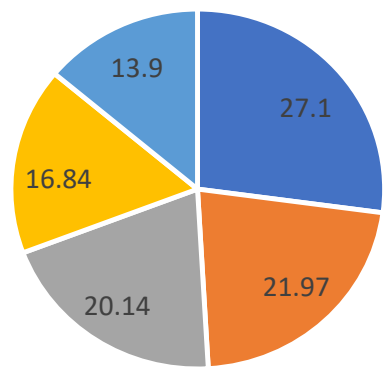

- $<1$ month 1 month to 2 years $\quad 2$ to 5 years 5 to 10 years $\square 10$ years

Figure-1: Illustrates the age distribution errors, $48.07 \%$ oferrors in children below the age of 2 years

Table-1: Observed errors in medication.

\begin{tabular}{|c|l|c|c|}
\hline & & Percentage & $\begin{array}{c}\text { Number of } \\
\text { errors }\end{array}$ \\
\hline Prescription errors & a. Incorrect dose & $21.97 \%$ & 60 \\
$34.06 \%$ - (93) & b. Inappropriate way of prescription & $12.08 \%$ & 33 \\
\hline Dispensing errors & a. Incorrect measurements & $15.01 \%$ & 41 \\
$56.04 \%-(153)$ & b. Incorrect Iv infusion rates & $24.90 \%$ & 68 \\
& c. Missed dose & $10 \%$ & 27 \\
& d. Inappropriate route and mode of prescription & $5.12 \%$ & 14 \\
& e. Extra dose & $1 \%$ & 3 \\
\hline Clerical errors $10 \%-$ & a. Errors in copying out doctors instructions & $8.05 \%$ & 22 \\
$(27)$ & b. Incorrect patients & $1.83 \%$ & 5 \\
\hline
\end{tabular}

Most of the reports were made by doctors and nurses.14 reports regarding missed dosages were made by the parents. The incidence involved dispensing errors, prescription errors and clerical errors. The error rate was 1 per 9.5 patients which is $10.5 \%$. Most of the errors were reported in patients below 2 years of age $(49.07 \%)$. Errors in other age groups were evenly distributed. Dispensing errors and clerical errors were attributed to nursing staff, these accounted for $66.04 \%$ of all errors. Incorrect IV infusion rate was most common error and was found to be $24.90 \%$ (68 errors). It was followed by prescribing incorrect dose (21.97\%). Incorrect measurements of medicine were found to be $15.01 \%$ ( 41 errors), followed 
Case Report

by inappropriate way of prescription (12.08\%), missed dose (10\%) and errors in coping doctors instructions $(8.05 \%)$. inappropriate route and mode of prescription $(5.12 \%)$, incorrect patients $(1.83 \%)$ and extra dose $(1 \%)$ were other medication errors reported. None of errors done by nurses were fatal.

Table-2: Drugsimplicated in medication errors.

\begin{tabular}{|c|c|c|}
\hline Drugs & Percentage of errors & No of errors \\
\hline Iv fluids & $30 \%$ & 82 \\
\hline Iv Antibiotics & $24.9 \%$ & 68 \\
\hline IV antimalarials & $15 \%$ & 41 \\
\hline Inotropes & $10 \%$ & 27 \\
\hline Other & $20.1 \%$ & 55 \\
\hline
\end{tabular}

The drugs which are implicated in medication errors include IV fluids (30\%), IV antibiotics (24.9\%) antimalarials (15\%) and Inotropes (10\%). Other (20.1\%), medicines reported in errors include amino acids infusion rate, intra lipids infusion dosage, propanol, octreotide infusion dosages, antiepileptics like lorazepam and midazolam, and oral medications like iron cotrimoxazole and doxycycline. Most of the errors in medication were IV fluids followed by antibiotics.

\section{Discussion}

In our study over a period of four months 273 errors $(10.5 \%)$ were reported at a rate of 1 in 9.5 patients (total patients 2600). The error rate in our study was high compared to other studies. The reason behind higher error rate might be due to voluntary reporting by doctors, nurses and even parents. Another reason may be due to inclusion of incorrect intravenous fluid infusion rate unlike other studies. In addition, our hospital caters to patients coming from nearby villages who are less educated. They were not able to inform the nurses about over dose or missed dose. Mothers were not able to dispense syrup or suspensions in milliliters as per the prescription; they used tea spoons which were of variable sizes and not graded.

Although the prescription errors were fewer than other types of errors, these were more life threatening than errors attributed to nurses. Misplacement of decimal point while calculating the dose is potentially fatal error. In our study two drugs aminophylline and midazolam were reported for misplacement of decimal and rectified by senior doctors before dispensing the drug.

Availability of various strengths of commonly used drugs in market is another factor for causing errors, it is therefore desirable to have uniformity in the strength of medicines in hospital [11]. It is possible to avoid errors if physicians restrict their prescription to those drugs they are familiar with [11]. Omission of drugs by nurses seems to be a serious error. Missed doses have serious consequences in diseases like bacterial meningitis. Due to overcrowding and lack of adequate number of nurses in our country and where nurse/patient ratio is very low can lead to errors [11]. Often there are problems in calculating doses which need conversion from milligrams to milliliters which may lead to overdose or under dose, especially of highly concentrated injections and it is noted that nurses were not careful in dispensing oral medications which where prescribed in milliliters of specific preparation [11].

In a UK study, L M Ross, J Wallace and J Y Paton reviewed five years of medication errors, reporting data from a large UK children's hospital [1]. A total of 195 errors were reported at a rate of $0.15 \%$ of admissions (one error per 662 admissions). This rate is very low compared to most published figures despite including error in IV fluids infusion rate. In the study incorrect intravenous infusion rate $(15.8 \%)$ was highest reported error similar to our study accounting for $24.9 \%$ followed by incorrect dose (21.97\%).

There is little data on errors in children in hospital. Raju et al reported iatrogenic medication error rates of $14.7 \%$ of all admissions to a PICU and NICU over a four-year period [12] while Vincer et al found 13.4 incidents per 1000 patient days over two years in an NICU [13]. In contrast, in a paediatric emergency department treating 55,000 children annually, Selbst et al found only 33 medication incidents in five years [14]. These variations in error reporting rates highlight the difficulties in making valid comparisons of reported error rates between studies. Such difficulties have been highlighted in previous studies [3]. Leape et al emphasized the influence that fear of punishment may have on error reporting and the improvement that may follow if immunity from disciplinary action is offered [6]. Vincer 
Case Report

et al also reported a substantial increase in the reporting of medication incidents after a change to a less punitive system [13]. It should, however, be recognized that voluntary systems may also detect only a fraction of medication errors [15]. The intensity of the search for errors is also likely to have an effect. Other studies have used much more intensive case finding mechanisms [4] Our study looked at data from a routine reporting system and did not make any additional effects to detect errors. Although the rate of reported error was low, many of the errors were similar to those found in other studies.

Nurses reported more errors than any other health care professional, in keeping with previous data $[12,14]$. The types of error and the drugs involved were also similar to previous studies $[12,13]$. The importance of checking calculations and of avoiding decimal points where possible has been emphasized $[16,17]$

Virtually all the publications on medication errors identify opportunities for systematic changes to reduce the risk of future errors. All too often, the prevalent culture is one of blame and punishment. Our finding that 99.27 of reported errors were classified as minor while $0.73 \%$ were potentially fatal may perhaps be interpreted as in keeping with down playing incidents as a result of fear of subsequent repercussions. Most errors are not a result of individual negligence but arise more from systemic organizational failures. Leape et al have emphasized the importance of a systems-based approach where the emphasis shifts from the individual making the error to the characteristics of the system within which they function [6]. But it is likely that only by understanding and modifying the underlying causes for medication errors will we be able to reduce future errors.

\section{Conclusion}

We can minimize errors by some modifications like

1. Electronic system of prescription and progress notes.

2. Check lists for medication to avoid overuse / missed dosing.

3. Avoid decimal points. If decimals are unavoidable, use a leading zero before the decimal point; avoid trailing zeroes after the decimal point [1].

4. Spell micrograms and nanograms in full. Avoid abbreviations [1].
5. Do not prescribe or prepare drugs in the middle of the ward round-retire to a quiet dedicated area and check all calculations with a calculator.

6. Verification of written notes by seniors.

7. Neat and legible handwriting with use of capital letters for all drugs.

8. Medication errors reporting system.

9. Syrups and suspensions dosages should be prescribed in milliliter or milligram and precise way of prescribing them help nurses to dispense them with the help of graduated measure eg., syringe or cup with gradations [11].

10. Another approach in busy ward is to educate mothers regarding drug dose timings and tell them to report to nurses in case of delay in treatment or missed dosage.

11. Pasting of important drugs and dosages charts at approximate places will help in immediate references for dose calculations.

Funding: Nil, Conflict of interest: None initiated, Perission from IRB: Yes

\section{References}

1. L M Ross, J Wallace, J Y Paton. Medication errors in a paediatric teaching hospital in the UK: five years operational experience Arch Dis Child 2000; 83: 492-497.

2. Guo JJ, Gibson JT, Gropper DM, et al. Empiric investigation on direct costs-of-illness and healthcare utilization of Medicaid patients with diabetes mellitus. Am J Manag Care. 1998 Oct;4(10):1433-46.

3. ASHP guidelines on preventing medication errors in hospitals. Am J Hosp Pharm. 1993 Feb;50(2):305-14.

4. Bates DW, Cullen DJ, Laird N, et al. Incidence of adverse drug events and potential adverse drug events. Implications for prevention. ADE Prevention Study Group. JAMA. 1995 Jul 5;274(1):29-34.

5. Brennan TA, Leape LL, Laird NM, et al. Incidence of adverse events and negligence in hospitalized patients. Results of the HarvardMedical Practice Study I. N Engl J Med. 1991 Feb 7;324(6):370-6. doi:10.1056/ NEJM 199102073240604. 


\section{Case Report}

6. Leape LL, Brennan TA, Laird N, et al. The nature of adverse events in hospitalized patients. Results of the Harvard Medical PracticeStudy II. N Engl J Med. 1991 Feb 7;324(6):377-84.

7. Bates DW, Leape LL, Petrycki S. Incidence and preventability of adverse drug events in hospitalized adults. J Gen Intern Med. 1993 Jun; 8 (6):289-94.

8. Koren G, Barzilay Z, Greenwald M. Tenfold errors in administration of drug doses: a neglected iatrogenic disease in pediatrics. Pediatrics. 1986 Jun;77(6):848-9.

9. Folli HL, Poole RL, Benitz WE, Russo JC. Medication error prevention by clinical pharmacists in two children's hospitals. Pediatrics. 1987 May;79(5): 718-22.

10. Shah KN, Dalal A. Medication compliance in children. Indian J Pediatr. 1989 Sep-Oct;56(5):645-52.

11. Aneja S, Bajaj G, Mehandiratta SK. Errors in medication in a pediatric ward. Indian Pediatr. 1992 Jun; 29(6):727-30.
12. Raju TNK, Keiskes S, Thorntorn JP, Perry M, Feldman S. Medication errors in neonatal pediatric intensive care unit. Lancet 1989,2: 374-376.

13. Vincer MJ, Murray JM, Yuill A, et al. Drug errors and incidents in a neonatal intensive care unit. A quality assurance activity. Am J Dis Child. 1989 Jun;143 (6): $737-40$

14. Selbst SM, Fein JA, Osterhoudt K, Ho W. Medication errors in a pediatric emergency department. PediatrEmerg Care. 1999 Feb;15(1):1-4.

15. Cullen DJ, Bates DW, Small SD, et al. The incident reporting system does not detect adverse drug events: a problem for quality improvement. Jt Comm J Qual Improv. 1995 Oct;21(10):541-8.

16. Koren G, Haslam RH. Pediatric medication errors: predicting and preventing tenfold disasters. J Clin Pharmacol. 1994 Nov;34(11):1043-5.

17.Zeroingin on medication errors.Lancet1997;349: 369 DOI: https://doi.org/10.1016/S0140-6736(05)62746-8

\section{How to cite this article?}

Chandra Deve Varma BSK, Balaji Bhusan Patnaik, Ratakonda Sruthi, Gangavaram sravan kumar Reddy, V.Venkatesh, Jogi Satyasree. Incidence of various medication errors in pediatrics in a tertiary care hospital. Int J Pediatr Res.2018;5(9):441-445. doi:10.17511/ijpr.2018.i09.02. 